
\title{
28 Research Soure \\ Adoption of Solid Biomass Fuel for Cooking: Implication on Health Outcomes
}

Edward Martey ( $\square$ eddiemartey@gmail.com )

Agricultural Research Institute, Ghana

Original article

Keywords: Solid biomass fuel, Tenancy and occupancy status, health outcomes, biprobit.

Posted Date: June 8th, 2021

DOl: https://doi.org/10.21203/rs.3.rs-543439/v1

License: (c) (i) This work is licensed under a Creative Commons Attribution 4.0 International License. Read Full License 


\title{
Adoption of Solid Biomass Fuel for Cooking: Implication on Health Outcomes
}

\author{
Edward Martey $^{1 *}$ \\ ${ }^{1}$ CSIR-Savanna Agricultural Research Institute, Ghana P.O. Box TL 52, Tamale, Ghana. \\ *Corresponding author. \\ E-mail address: eddiemartey@gmail.com (E. Martey).
}

\section{Authors profile}

Edward Martey (Email: eddiemartey@gmail.com; ORCID ID: 0000-0002-6933-3685) is an Agricultural and Applied Economist at the CSIR-Savanna Agricultural Research Institute and a visiting scholar at the University of Illinois at Urbana-Champaign. He received his BSc and MPhil (Agricultural Economics) and PhD (Agricultural and Applied Economics) degrees from the University of Ghana and University of Illinois at Urbana-Champaign, respectively. He is currently the Head of the Socio-economic Section of CSIR-SARI. His key research interests are in the areas of development economics, energy and environment, management of innovation platforms, agricultural adoption and commercialization, gender, value-chain development, and impact evaluation. Dr. Martey has collaborated with international organizations such as University of Illinois at Urbana-Champaign, AGRA, AfricaRice, IITA, IFPRI, ICRISAT, JICA and PenState University to implement projects that focus on food security, time-poverty and women empowerment, technology dissemination, gender, value-chain development, agricultural mechanization, and soil fertility management.

LinkedIn: https://www.linkedin.com/in/edward-martey-ba5b61127/

ResearchGate: https://www.researchgate.net/profile/Edward_Martey/research

Mendeley: https://www.mendeley.com/profiles/edward-martey2/publications/

\section{Acknowledgments}

This study used the Ghana Living Standard Survey Seven (GLSS 7) data provided by the Ghana Statistical Service (GSS). The Savanna Agricultural Research Institute (SARI) of the Council for Scientific and Industrial Research (CSIR) is acknowledged for the administrative support. 


\section{Adoption of Solid Biomass Fuel for Cooking: Implication on Health Outcomes}

\section{Abstract \\ Background}

The Sustainable Development Goal (SDG) seven highlights the need to ensure access to affordable, reliable, sustainable and modern energy for all. Improving access to reliable and affordable modern energy for cooking have far-reaching benefits on human health. This study examines the relationship between the adoption of solid biomass fuel (SBF) for cooking and health outcomes.

\section{Methods}

The study used a nationally representative household-level data from a survey of 14,009 households in Ghana. For the econometric analysis, a biprobit model was employed to estimate the effect of SBF adoption on health outcomes.

\section{Results}

The results show that adoption of SBF increases the probability of a household reporting ill-health and reporting frequently to a health facility by $25 \%$ each, respectively.

\section{Conclusions}

The findings of the study imply that ensuring affordability of clean fuel will enable households in developing countries to transition from traditional biomass to clean cooking fuels. Government programs and policies that aim at encouraging the use of clean fuel for cooking must target private occupants and homeowners.

Keywords: Solid biomass fuel; Tenancy and occupancy status; health outcomes; biprobit. 


\section{Introduction}

Increasing access to clean fuel for cooking while maintaining the quality of the environment and improving human health is an important development issue (AGECC, 2010; World Bank, 2011a). A report by the International Energy Agency (IEA) estimate that over 900 million people in subSaharan Africa (SSA) use solid biomass fuel (SBF) such as fuelwood, crop residue, dung, and charcoal for cooking (IEA, 2019). Rural areas in developing countries record about 2.64 billion people using solid biomass fuel such as fuelwood, charcoal, dung, and crop residue for cooking (IEA, 2013a). Bonjour et al. (2013) reported that about $60 \%$ of households in Africa and South East Asia uses solid fuel for cooking. The rate at which developing countries use SBF requires a well-coordinated effort to curb the situation.

Meanwhile, studies have shown that the use of SBF for cooking have a severe impact on forest and land degradation, climate change, and human health (referred to as the triple effect of SBF) (Bailis et al., 2015; Lim et al., 2012; Smith et al., 2013; World Health Organization, 2006). For example, Johnson and Chiang (2015) find that limited solid fuel combustion results in substantial health risks. Martin et al. (2011) and Shindell et al. (2012) demonstrate that the use of SBF for cooking is associated with a considerable proportion of climate-relevant emissions. WHO (2014)

finds that the annual exposure to air pollution from SBF smoke is a principal cause of global disability and mortality with over 4 million deaths. Clough (2012) show that in East Africa, respiratory diseases triggered by air pollution account for about 14,300 deaths in Kenya and 18,000 deaths in Tanzania each year. 
The United Nations recognizes this important development issue especially in developing countries and thus puts forward a transformational road map enshrined in the Sustainable Development Goals (SDG's) to champion this cause. The Sustainable Development Goal (SDG) seven highlights the need to ensure access to affordable, reliable, sustainable and modern energy for all (United Nations, 2015). More specifically and per the 2030 target, the expectation is that there will be an "enhanced international cooperation to facilitate access to clean energy research and technology, including renewable energy, energy efficiency, and advanced and cleaner fossilfuel technology, and promote investment in energy infrastructure and clean energy technology" (United Nations, 2015). The Sustainable Energy for All (SE4ALL) initiative aims at i) ensuring universal access to modern energy services, ii) doubling the global rate of improvement in energy efficiency and iii) doubling the share of renewable energy in the global energy mix by 2030 (UN, 2013).

Since the inception of the initiative, there has been several studies on the adoption of modern fuel for cooking, improving the sustainability of biomass cooking fuels, preferences for improved cooking stoves (ICS) ${ }^{1}$ and their impact on health outcomes. A study by Martey (2019) show that in Ghana renters use firewood, candle, and crop residue for lighting and use modern (LPG), transition (charcoal), and other fuel (electricity, crop residue, kerosene, sawdust, and animal waste) for cooking. The United Nations Economic Commission for Africa 2014 report indicates that people still rely on wood, charcoal, and farm by-products for cooking in East Africa due to population growth and cost hurdles (UNECA, 2014; Gould \& Urpelainen, 2018). A review by

\footnotetext{
${ }^{1}$ An improved biomass cookstove is one that provides fuel savings and convenient use, including reduced or similar cooking times. Reduced fuel requirements in turn can translate into either reduced expenditures or household time savings that can be used for other purposes, including leisure (Gebreegziabher et al., 2018).
} 
Mallas \& Timilsina (2014) find that the cost of improved cooking stoves outweighs the perceived health benefits of using improved stoves and the financial benefits from fuel savings. Bensch et al. (2015) find 10\% take-up rates of improved cooking stoves in Burkina Faso largely due to the upfront investment costs rather than access to information, taste preferences, or a woman's role in the household. Though medical research has established links between air pollution caused by open fires and illness including pneumonia, eye infections (McCracken et al., 2011), some literature on the health effects of modern fuel is mixed. Using a large-scale randomized control trial in India, Hanna et al. (2016) find that not all improved cooking stoves decrease fuelwood consumption and the health burden. One possible reason is the low willingness to pay for improved stoves and little interest in health impacts (Dherani et al., 2008; Kan et al., 2011; Mobarak et al., 2012). According to Miller \& Mobarak (2015), households' decision on the adoption of modern fuel is influenced largely by monetary reasons and liquidity constraints rather than health considerations. Mortimer et al. (2016) find no evidence of cleaner-burning biomass-fueled cookstoves on the risk of pneumonia in young children in rural Malawi. Using a randomized control trial to evaluate a stove designed to reduce fuelwood but not smoke emissions in Senegal, Bensch \& Peter (2015) find a considerable reduction in fuelwood consumption, smoke exposure, respiratory disease symptoms, and eye problems among adopters.

The literature shows a mixed result in terms of the health effects of SBF. Most of the studies reviewed did not account for rental and occupancy status in the choice of SBF and their effect on health outcomes. Secondly, policies relating to renting and home occupancy differ significantly across continents. Ghana presents a unique case study for undertaking this study, given that about $89.2 \%$ of households use biomass energy compared with $10.8 \%$ which uses modern energy sources 
(Mensah \& Adu, 2015). This study builds on an earlier study by Martey (2019) by establishing the link between SBF and health outcomes measured by the probability of reporting ill-health and reporting frequently to a health facility due to ill-health. The study accounted for the endogeneity in the adoption of SBF and controlled for rental and occupancy status in the model. The result of the biprobit model indicates that the adoption of SBF for cooking increases the probability of a household reporting ill-health and reporting frequently to a health facility. A differential analysis showed that charcoal has a modest effect on health outcomes relative to using wood as fuel for cooking.

The rest of the paper is structured as follows: Section 2 describes the data while section 3 presents the empirical strategy. Section 4 presents empirical results and section 5 discusses the result. Section 6 provides the concluding remarks.

\section{Data and descriptive characteristics}

\subsection{Data}

The study relied on the seventh round of the Ghana Living Standard Survey (GLSS), a nationally representative household survey conducted over a period of 12 months (October 10, 2016 to October 9, 2017) by the Ghana Statistical Service (GSS). The GSS employed a two-stage stratified sampling design to sample 15,000 households across the ten administrative regions ${ }^{2}$ of Ghana. In the first stage, 1,000 census enumeration areas (EAs), consisting of $561(56.1 \%)$ rural EAs and 439 (43.9\%) urban EAs were sampled. The EAs are the primary sampling units stratified into the ten administrative regions of Ghana based on the population in each of the regions. In the second

\footnotetext{
${ }^{2}$ The administrative regions of Ghana as of the time of the survey was 10 but currently new regions have been created bringing the total number of regions to 16 .
} 
stage, households per EA were randomly sampled based on the regional population shares. A total of 14009 households out of the 15,000 sample households were successfully enumerated by trained enumerators employed by the GSS. Table 1 shows the regional, EAs, and household sample distribution.

Table 1: Regional Distribution of EAs and Households

\begin{tabular}{lcccccc}
\hline Region & Population & $\begin{array}{c}\text { Regional } \\
\text { Share }\end{array}$ & $\begin{array}{c}\text { Households } \\
\text { allocation }\end{array}$ & Final EAs & Urban EAs & Rural EAs \\
\hline Western & $2,307,385$ & 0.10 & 1,470 & 98 & 41 & 57 \\
Central & $2,113,763$ & 0.09 & 1,410 & 94 & 44 & 50 \\
Gt. Accra & $3,888,237$ & 0.16 & 1,650 & 110 & 100 & 10 \\
Volta & $2,086,557$ & 0.09 & 1,440 & 96 & 32 & 64 \\
Eastern & $2,574,543$ & 0.11 & 1,500 & 100 & 43 & 57 \\
Ashanti & $4,671,948$ & 0.19 & 1,800 & 120 & 72 & 48 \\
Brong Ahafo & $2,265,434$ & 0.09 & 1,430 & 95 & 42 & 53 \\
Northern & $2,445,061$ & 0.10 & 1,470 & 98 & 30 & 68 \\
Upper East & $1,034,688$ & 0.04 & 1,420 & 95 & 20 & 75 \\
Upper West & 688,328 & 0.03 & 1,410 & 94 & 15 & 79 \\
National & $24,075,944$ & 1.00 & 15,000 & 1,000 & 439 & 561 \\
\hline
\end{tabular}

The survey captured information on household demographics (gender, age, number of males and females, education, and household size), labor market, migration, remittances, income, and expenditures (food, health, education, housing, consumer goods and durables), agricultural production, household investment decisions, poverty, the main fuel for cooking and lighting. This study focuses on the section of the GLSS 7 that captures a household's choice of biomass fuel for cooking, tenure mode (rented or owned), food hardship, dwelling type (compound or private residence), housing characteristics, and health outcomes (hospitalized due to ill-health and frequency of visit to a health facility for treatment). The data is limited in analyzing multiple fuel use (referred to as "fuel stacking") given that households interviewed were asked to identify the main biomass fuel for cooking. Second, the choice of biomass fuel type for cooking and the health outcome variables are dummy and not continuous, therefore, limiting the analysis to probability 
models. There is no alternative dataset with such wide coverage of households' biomass energy use in Ghana, thus making the GLSS 7 an ideal dataset for this study.

The main solid biomass fuel for cooking are wood, charcoal, and crop residue and animal waste. These fuel sources reflect the preferences of households given that some households are more likely to use certain types of cooking sources based on access, location, wealth status, housing characteristics, and other innate characteristics. The three solid biomass fuel types were categorized into "users" while households who use neither of these fuel types are classified as "non-users." I construct an indicator (dummy - 1 if the household uses any of the three solid biomass fuel and 0 otherwise) for biomass fuel using the existing information on the types of solid biomass fuel adopted by the households where users. Similarly, an indicator for dwelling type and tenure mode was constructed using the existing information on housing characteristics (refer to Martey, 2019 for further details on the construction). To capture the geographical differences in population dynamics, access to infrastructure, prices, donor and government support programs, and the cost of cooking fuel type, I included regional dummies as controls in the model.

Figures 1 and 2 show the administrative regions of the study area. The maps show the relationship between the adoption of SBF and health outcomes for each of the administrative regions. The colour of the map represents the proportion of households that adopt SBF, while the size of the ball represents the proportion of households that report ill-health in each of the administrative regions. The data shows that users of SBF increased from 2012 to 2016 for households in Ashanti, Central, Eastern, Greater Accra, Upper East, Volta, and Western regions. Apart from the households in the Central Region, all the households in the other regions experienced a decline in 
the number of reported ill-health. Generally, there is a modest positive relationship between the use of SBF and reported health outcomes. However, the relationship in 2017 is mixed for households in the Greater Accra Region where a high proportion of users of SBF do not necessarily translate to a high number of reported ill-health. In 2012, a decline in the number of users of SBF in the Greater Accra Region leads to an increase in the number of reported ill-health relative to the reported ill-health in 2017.
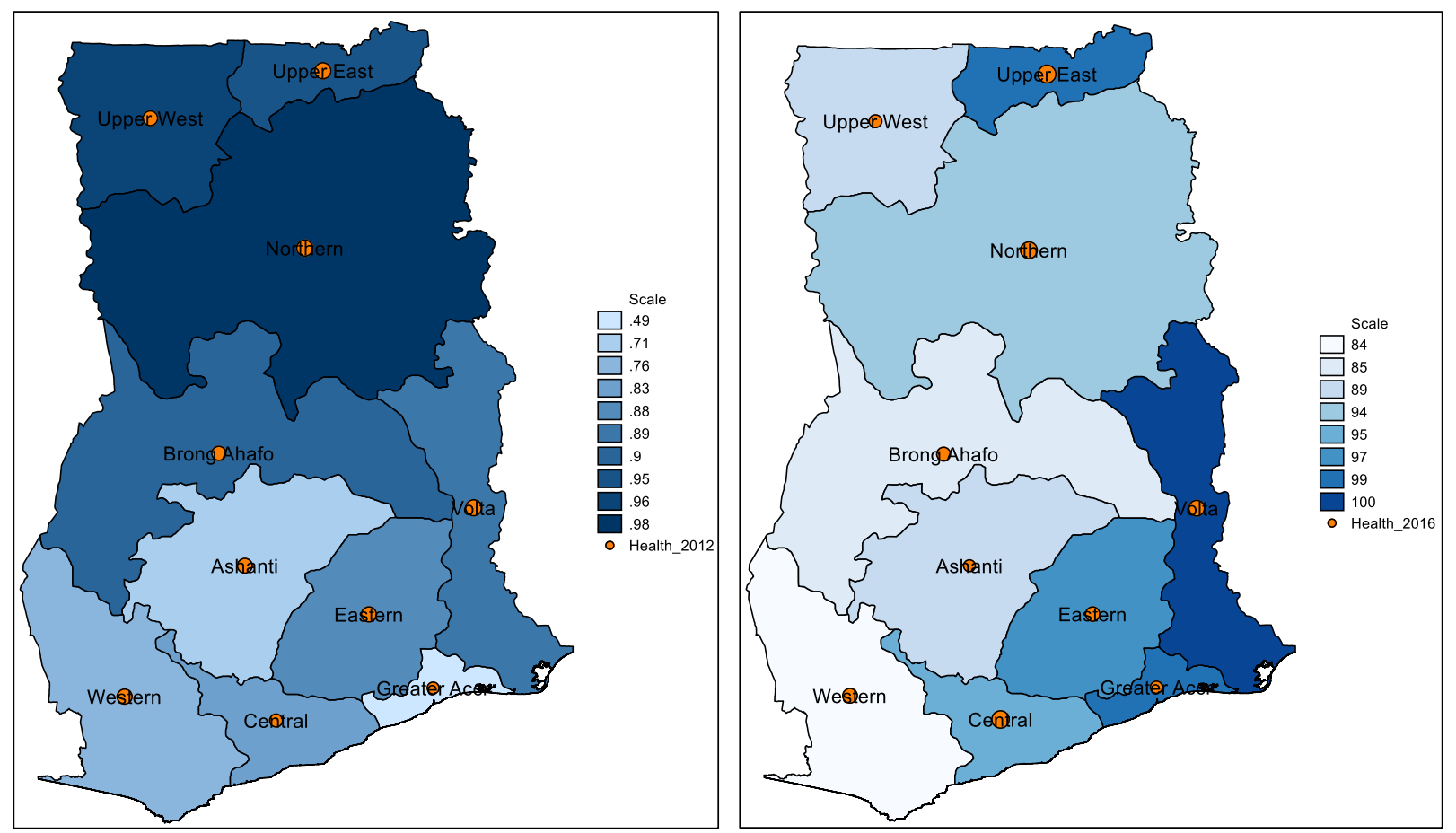

Fig. 1. Solid biomass fuel and health outcomes for 2012

Fig. 2. Solid biomass fuel and health outcomes for 2016

Table 2 shows the distribution of the solid biomass fuel types used by the sampled households. About $61 \%, 37 \%$, and $2 \%$ of the sampled households use wood, charcoal, and crop residue/animal waste, respectively for cooking. The annual expenditure on solid biomass fuel for cooking is GHS263.267 (US\$59.83). Compared to wood and crop residue/animal waste expenditures, households spend more on charcoal for cooking. This has implications for the environment and 
quality of animal and human life. With respect to the health outcomes, about $28 \%$ and $27 \%$ of the sampled households report ill-health and frequency of ill-health, respectively.

Table 2: Solid biomass fuel type and expenditure

\begin{tabular}{|c|c|c|c|c|}
\hline & Mean & Std. Dev. & Min & Max \\
\hline \multicolumn{5}{|l|}{ Biomass solid } \\
\hline Wood & 0.613 & 0.487 & 0 & 1 \\
\hline Charcoal & 0.371 & 0.483 & 0 & 1 \\
\hline Crop residue and animal waste & 0.016 & 0.124 & 0 & 1 \\
\hline \multicolumn{5}{|l|}{ Expenditure on solid biomass fuel } \\
\hline Wood expenditure & 247.849 & 246.101 & 1.5 & 1080 \\
\hline Charcoal expenditure & 275.988 & 228.801 & 2 & 1080 \\
\hline Crop residue and animal waste expenditure & 172.454 & 141.617 & 17.52 & 420 \\
\hline Expenditure for all biomass solid & 263.267 & 236.834 & 1.5 & 1,080 \\
\hline \multicolumn{5}{|l|}{ Health outcomes } \\
\hline Reported ill-health & 0.275 & 0.447 & 0 & 1 \\
\hline Frequency of ill-health & 0.268 & 0.443 & 0 & 1 \\
\hline
\end{tabular}

Notes: Exchange rate at the time of the survey is 1US\$=GHS4.40 (Source: Bank of Ghana, 2017).

Table 3 presents the mean and mean differences of the socio-economic variables based on the adoption of solid biomass fuel. Based on the P-value computed using the Welch t-tests, the results show the users and non-users of solid biomass fuel were unbalanced except for the years of formal education, household size, male and female children below five years, male and female between 5-18 years, adult male above 18 years, total remittance, rental status, and poverty status. Compared to non-users of solid biomass fuel, users on average have less male household heads, older household heads, more adult female above 18 years, more members dwelling in a compound house, less food insecurity, and unemployment rate. 
Table 3: Mean comparison for socio-economic variables

\begin{tabular}{lcccc}
\hline & & Standard & \multicolumn{2}{c}{ Mean difference } \\
\cline { 4 - 5 } Demographic variables & Mean & deviation & (Non-users) - (Users) & P value \\
\hline Gender (1=male) & 0.669 & 0.471 & 0.037 & 0.032 \\
Age & 47.996 & 15.952 & -1.372 & 0.024 \\
Years of formal education & 4.640 & 6.327 & -0.142 & 0.552 \\
Household size & 4.673 & 2.944 & -0.119 & 0.352 \\
Male children below 5 years & 0.321 & 0.599 & 0.041 & 0.106 \\
Female children below 5 years & 0.301 & 0.564 & -0.023 & 0.278 \\
Male children (5-18 years) & 0.999 & 1.226 & -0.055 & 0.287 \\
Female children (5-18 years) & 0.938 & 1.151 & -0.036 & 0.436 \\
Adult male (above 18 years) & 1.023 & 0.873 & 0.046 & 0.172 \\
Adult female (above 18 years) & 1.309 & 0.863 & -0.118 & 0.000 \\
Total remittances out & 379.188 & 1108.748 & 48.678 & 0.325 \\
Rental status (1=rent) & 0.392 & 0.488 & 0.015 & 0.432 \\
Dwelling status (1=compound) & 0.532 & 0.499 & -0.165 & 0.000 \\
Poverty status (1=poor) & 0.671 & 0.470 & 0.018 & 0.305 \\
Food hardship (1=food insecure) & 0.585 & 0.493 & 0.049 & 0.008 \\
Unemployment rate & 0.070 & 0.009 & 0.001 & 0.007 \\
\hline
\end{tabular}

The results show a statistically significant differences in all the housing characteristics between users and non-users except for the number of sleeping rooms, share a dwelling, expenditure on house maintenance, and cemented outer walls (Table 4). Compared to non-users of solid biomass fuel, users tend to have improved housing characteristics.

Table 4: Mean comparison for geographic variables

\begin{tabular}{lcccc}
\hline & & & \multicolumn{2}{c}{ Mean difference } \\
Housing variables & Mean & Std. Dev. & (Non-users) - (Users) & P value \\
\hline Number of rooms & 2.280 & 1.666 & -0.142 & 0.014 \\
Number of sleeping rooms & 1.936 & 1.296 & -0.076 & 0.105 \\
Share dwelling & 0.018 & 0.132 & 0.005 & 0.328 \\
Expenditure on house maintenance & 146.973 & 1504.580 & -28.502 & 0.236 \\
Mud for outer walls (1=yes) & 0.538 & 0.499 & 0.036 & 0.058 \\
Cement for outer walls (1=yes) & 0.382 & 0.486 & -0.005 & 0.795 \\
Earth and mud floor (1=yes) & 0.145 & 0.352 & 0.104 & 0.000 \\
Concrete floor (1=yes) & 0.833 & 0.373 & -0.097 & 0.000 \\
Stone floor (1=yes) & 0.004 & 0.062 & -0.003 & 0.067 \\
Metal roof (1=yes) & 0.810 & 0.392 & 0.069 & 0.000 \\
Slate roof (1=yes) & 0.083 & 0.277 & -0.075 & 0.000 \\
Thatch roof (1=yes) & 0.067 & 0.250 & -0.017 & 0.039 \\
Other material for roof (1=yes) & 0.039 & 0.194 & 0.024 & 0.008 \\
\hline
\end{tabular}


Table 5 reports the mean comparison for geographical variables representing the location of the sampled households. The results show that users and non-users of solid biomass fuel were unbalanced in terms of the geographic variables except for households located in the Northern Region. Users of solid biomass fuel are predominantly located in urban areas. Non-users of solid biomass fuel are less likely to stay in the Central, Greater Accra, Volta, Eastern, and Upper West regions when compared to the users. However, users are less likely to reside in Western, Ashanti, Brong-Ahafo, and Upper West regions.

Table 5: Mean comparison for geographic variables

\begin{tabular}{lcccc}
\hline & & Standard & \multicolumn{2}{c}{ Mean difference } \\
\cline { 4 - 5 } Geographical variables & Mean & deviation & (Non-users) - (Users) & P value \\
\hline Urban (1=yes) & 0.322 & 0.467 & -0.064 & 0.000 \\
Western Region (1=yes) & 0.090 & 0.287 & 0.127 & 0.000 \\
Central Region (1=yes) & 0.092 & 0.289 & -0.034 & 0.000 \\
Greater Accra Region (1=yes) & 0.053 & 0.223 & -0.045 & 0.000 \\
Volta Region (1=yes) & 0.104 & 0.305 & -0.107 & 0.000 \\
Eastern Region (1=yes) & 0.104 & 0.306 & -0.063 & 0.000 \\
Ashanti Region (1=yes) & 0.101 & 0.301 & 0.055 & 0.000 \\
Brong-Ahafo Region (1=yes) & 0.100 & 0.301 & 0.125 & 0.000 \\
Northern Region (1=yes) & 0.121 & 0.326 & -0.015 & 0.208 \\
Upper East Region (1=yes) & 0.118 & 0.322 & -0.114 & 0.000 \\
Upper West Region (1=yes) & 0.118 & 0.322 & 0.072 & 0.000 \\
\hline
\end{tabular}

The study employed the binscatter plot to demonstrate the relationship between solid biomass fuel and welfare (income) while accounting for region-specific effect. The relationship demonstrates the energy ladder hypothesis for both rural and urban dwellers (Fig. 3). Rural and urban dwellers show a similar relationship for the solid biomass fuel types and welfare. The use of wood and crop residue/animal waste decreases with an increase in household welfare. The gap between rural and urban dwellers with respect to the use of wood is wide at the lower welfare but tends to be narrow at higher levels of welfare. With respect to the use of crop reside/animal waste, the gap closes at 
the higher levels of welfare. The figure suggests that as income increases both rural and urban dwellers tend to use less wood and crop residue/animal waste. However, both urban and rural dwellers recorded a positive relationship between charcoal use and welfare. The gap between rural and urban dwellers in terms of charcoal use is wide at the lower level of welfare and reduces at a higher level of welfare. Compared to urban households, rural households use more charcoal as income increases. A positive relationship is observed between solid biomass fuel expenditure and welfare irrespective of the location of the households.
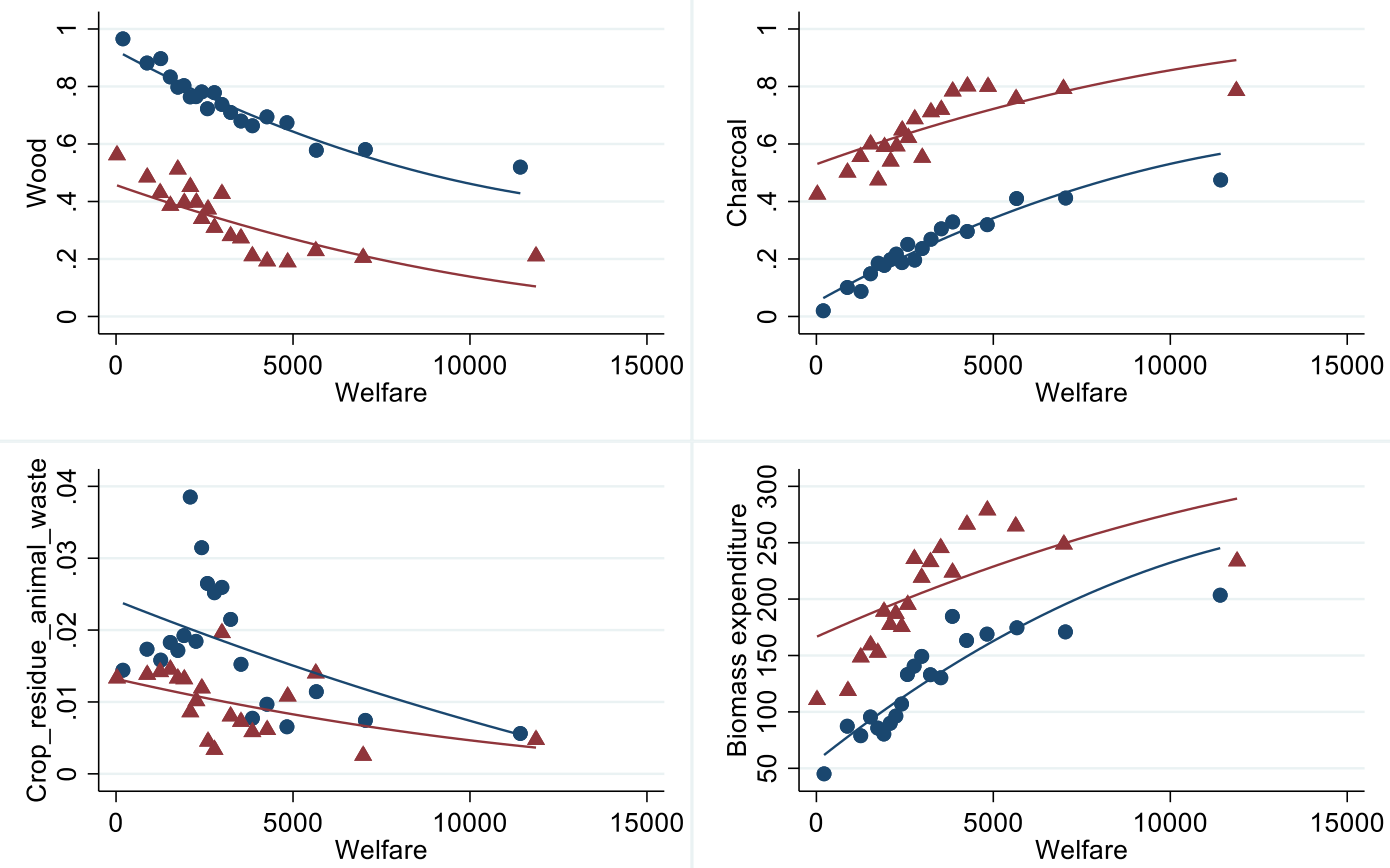

- Urban $\Delta$ Rural

Fig. 3. Solid biomass fuel and expenditure by location

\section{Empirical strategy}

The identification strategy used in the model is based on the heterogeneity in the use of solid biomass fuel. This study hypothesized that the adoption of a specific solid biomass fuel type is 
expected to impact negatively on health outcomes (reported to a health facility due to illness and frequency of visit). Assuming the health outcome variables are a linear function of solid biomass fuel adoption $\left(I_{i j}\right)$, along with a vector of socio-economic variables $\left(X_{i j}\right)$, housing characteristics $\left(H_{i j}\right)$, and regional dummies $\left(R_{v}\right)$, then the main equation estimated is specified as follows:

$$
y_{i j}=\alpha_{0}+\beta^{\prime} I_{i j}+\gamma^{\prime} X_{i j}+\theta^{\prime} H_{i j}+\omega^{\prime} R_{v}+\varepsilon_{i j}
$$

where $y_{i}$ is a dummy health outcome variable previously defined; $i$ and $j$ denote individual and household, respectively, and $\varepsilon_{i j}$ is an independent and identically distributed (i.i.d.) error term; $\beta$, $\gamma, \theta$, and $\omega$ are parameters to be estimated. The coefficient on solid biomass fuel is expected to be statistically significant and negative $(\beta>0)$, indicating that increase in the adoption of SBF is associated with higher probability of reporting to a health facility due to ill-health and frequency of visit.

Estimation of equation (1) using a linear probability model (LPM) will lead to a biased and an inconsistent estimate of $\beta$ due to a correlation between $\operatorname{SBF}$ variable $\left(I_{i j}\right)$ and the error term $\left(\varepsilon_{i j}\right)$ which may be a result of reverse causality. SBF influences health outcomes and consequently, household members who are indisposed due to ill-health are likely to choose a type of SBF. Secondly, the biased estimate may be due to correlation between an omitted variable (observed and/or unobserved) that influences both SBF and health outcomes. The SBF is likely to be influenced by unobservable characteristics (e.g., innate abilities/motivation, managerial skills, and innovativeness) that may be correlated with the outcome variables. For example, households that are highly motivated and have high preferences for clean fuel due to their participation in environmental campaigns may prefer fuel that are less destructive to the environment. I controlled 
for confounders that may influence health outcomes in vectors $X_{i j}, H_{i j}$, and $R_{v}$ to avoid the regionspecific effect on health outcome due to level of urbanization or unobservable effects such as timeinvariant geographical and climate conditions, ethnicity, social norms, and cultural traditions (Umberger et al., 2015).

The potential endogeneity problem in the use of the LPM is addressed using the biprobit model developed by Heckman (1978). The binary nature of the SBF and the health outcomes make the biprobit model an ideal estimation model for this study. Several studies have applied the biprobit model in most development studies (e.g. Acosta, 2011; Evans \& Schwab, 1995; Martey, 2019; Souza, 2018). The specification of the model is based on Greene (2003) where two binary dependent variables based on the assumption that independent and identically distributed (iid) errors in each equation are correlated. The first stage estimation is modeled such that adoption of SBF is determined by a set of exogenous covariates and instruments as follows:

$$
I_{i j}=\delta+S_{i j} \vartheta+\mu_{i j}
$$

where $S_{i}=\left[X_{i j}, H_{i j}, R_{v}, Z_{i j}\right]$ is a vector of explanatory variables (previously defined) and the instrument $Z_{i j}$ (information on the environmental effect on $\mathrm{SBF}$ ); $\delta$ and $\vartheta$ are parameters to be estimated, and $\mu_{i j}$ is the random error term. The parameters in equations (1) and (2) are identified through a simultaneous maximum likelihood estimation. Refer to Martey, (2019) and Wooldridge, (2010) for a more detailed explanation of the estimation procedure of the biprobit model.

The validity of the instruments is based on satisfying two core assumptions: (1) relevance and (2) exogeneity. The instrument should be relevant such that the instrument should be highly correlated with the endogenous variable, $\operatorname{SBF}\left(I_{i j}\right)$. The falsification test is conducted to establish the validity 
of the instrument. A falsification test certifies the admissibility of the selection instrument as a valid instrument: if a variable is an appropriate selection instrument, it will only influence the SBF adoption decision, but not the health outcomes of the non-adopters. Table A1 shows that the instrument is valid. The first stage results show that the instrument is highly significant in the SBF adoption model. The strength of our instruments is tested based on the F-statistic proposed by Stock et al. (2012) and the robust test for weak instrument proposed by Olea \& Pflueger (2013). Secondly, the exogeneity condition requires that the instrument is uncorrelated with omitted variables that may affect the dependent variables (health outcomes). The diagnostic test of endogeneity of the model is reported in Table 6. The non-significance of the robust score chi2 value leads to a rejection of the alternate hypothesis of endogeneity. This indicates that there is no endogeneity in the estimation of SBF adoption on health outcomes. However, I included an instrument to increase the robustness of the results.

Han and Vytlacil (2017) and Altonji et al. (2005) proposed that identification of the parameters can be achieved by the nonlinearity of the biprobit model especially where the instrument included in the structural equation is weak. Furthermore, they argue that if the vectors of exogenous controls in both equations are the same for both structural equations, then the exclusion restrictions are not necessary for identification.

\section{Empirical results}

\subsection{Determinants of solid biomass fuel adoption}

The first stage results showing the factors influencing the adoption of SBF is reported in Table 6. Household size is negatively associated with the adoption of SBF. The result suggests that larger households prefer modern fuels to dirty fuels. A unit increase in household size increases the 
probability of adopting SBF by $1 \%$. Disaggregating the household size reveals that a unit increase in the number of males between 5 to 18 years increases the adoption of SBF by $1 \%$ while a unit increase in the number of females above 18 years increases the adoption of SBF by $2 \%$. The energy literature shows that the relationship between household size and fuel switching is ambiguous (Muller \& Yan, 2018). However, the result confirms the findings of some studies (Baiyegunhi \& Hassan, 2014; Gupta \& Köhlin, 2006) that established a statistically significant negative relationship between household size and choice of dirty fuel for cooking in developing countries.

Rental status is negatively associated with SBF adoption. Household heads who are living in a rented apartment are $2 \%$ less likely to adopt SBF for cooking relative to owner-occupied households. The result confirms the findings of Ouedraogo, (2006) and Pundo \& Fraser (2006) but contradicts the widely held view that homeowners are more likely to use cleaner fuels than tenants (Baiyegunhi \& Hassan, 2014; Maria de Fatima et al., 2010). Following the argument of Martey (2019), renters incur an initial investment cost (painting, cleaning, and installation of gadgets) in occupying a new or previously occupied apartment. The high initial investment and future costs coupled with the tenancy agreement may influence the occupant to adopt clean fuel for cooking.

Compared to private occupants, households who dwell in a compound house are 5\% more likely to use SBF for cooking. The result is consistent with the findings of Kholodilin et al. (2017) and Myers, (2020). Their study showed that the tendency to free ride is likely when housing units are shared with landlords. Second, a large proportion of the households that dwell in compound houses use an external kitchen which does not encourage the use of modern clean fuels that is associated with some initial investment in equipment (Baiyegunhi \& Hassan, 2014). In a typical compound 
house in Ghana, occupants do not share a kitchen if the dwelling is rented. However, there is a common kitchen used by the occupants if the dwelling is owned and shared by a large family. The occupancy mode may determine the investment and choice of specific energy for cooking. For example, households that own and share dwelling units are more likely to use SBF given that labour for collecting firewood, crop residue, and animal dung is readily available.

Contrary to expectation, the probability of adopting SBF for cooking among food-insecure households is $2 \%$ less than food-secure households. Information about SBF is positively associated with the adoption of SBF. Households with information about SBF are $1 \%$ more likely to adopt SBF relative to households that do not have information about SBF. Households that are foodinsecure may not necessarily be clean energy insecure. However, the duration of using clean fuel may be problematic for food insecure households in the future. It is possible for food insecure households to switch between SBF and clean fuel for cooking depending on their budget constraint.

Information allows individual to make informed decisions regarding innovations and technologies that are likely to improve their welfare. Households located in Western and Brong-Ahafo regions are less likely to adopt SBF for cooking while households located in Central, Greater Accra, Volta, Eastern, Northern and Upper East regions are more likely to adopt SBF for cooking. Charcoal is mostly produced in the northern part of Ghana and transported to southern Ghana. This may account for the use of SBF in northern and major parts of Southern Ghana. 
Table 6: Probit estimates of the adoption of SBF for cooking

\begin{tabular}{lccc}
\hline Variables & Marginal effect & Standard error & P value \\
\hline Sex & 0.002 & 0.007 & 0.793 \\
Age & 0.000 & 0.000 & 0.959 \\
Years of education & 0.000 & 0.000 & 0.300 \\
Household size & -0.008 & 0.005 & 0.091 \\
Male (5-18 years) & 0.009 & 0.005 & 0.076 \\
Female (5-18 years) & 0.007 & 0.005 & 0.212 \\
Males above18 years & 0.001 & 0.006 & 0.909 \\
Females above18 years & 0.015 & 0.006 & 0.015 \\
Receive remittances & 0.000 & 0.000 & 0.117 \\
Renting & -0.018 & 0.006 & 0.003 \\
Dwelling & 0.050 & 0.005 & 0.000 \\
Poverty status & 0.009 & 0.006 & 0.149 \\
Food hardship & -0.015 & 0.005 & 0.004 \\
Urban & 0.009 & 0.006 & 0.114 \\
Western Region & -0.015 & 0.009 & 0.093 \\
Central Region & 0.059 & 0.011 & 0.000 \\
Greater Accra Region & 0.117 & 0.019 & 0.000 \\
Volta Region & 0.199 & 0.024 & 0.000 \\
Eastern Region & 0.086 & 0.012 & 0.000 \\
Ashanti Region & 0.006 & 0.010 & 0.527 \\
Brong-Ahafo Region & -0.019 & 0.009 & 0.035 \\
Northern Region & 0.035 & 0.009 & 0.000 \\
Upper East Region & 0.162 & 0.016 & 0.000 \\
Number of rooms & 0.001 & 0.002 & 0.567 \\
Share dwelling & -0.041 & 0.026 & 0.104 \\
Information on SBF & 0.011 & 0.005 & 0.034 \\
\hline No. of observation & 10,623 & & \\
Wald chi2(28) & $457.86 * * *$ & & \\
Pseudo R2 & 0.131 & & \\
Robust score chi2(1) & 0.019 & & \\
\hline & & & \\
\hline
\end{tabular}

\subsection{LPM and Probit estimates of determinants of health outcomes}

The results from estimating equation (1) using the linear probability and the probit models are reported in Table 7. The socio-economic, geographical, and housing characteristics are controlled for in all the models to attenuate the potential bias in the estimation. A detailed description of the controls is summarized in Tables 3-5. The mean health outcomes of the non-users of SBF for cooking are in brackets. The results highlight the marginal effects of the determinants of SBF. The magnitude of the marginal effects of the probit estimates is consistently higher than the estimates of the LPM. The adoption of SBF increases the probability of reporting ill-health and frequency 
of reporting ill-health by $5 \%$ and $4 \%$, respectively compared to the mean level. The magnitude of the effect is larger for the probit model where households that adopt SBF for cooking are $16 \%$ and $14 \%$ more likely to report to a health facility due to ill-health and the frequency of reporting illhealth, respectively. The results suggest that households that use SBF for cooking are more likely to report to a health facility due to ill-health and may also increase the probability of reporting to the health facility more frequently. This indicates that creating awareness on the use of cleaner fuels is likely to improve the health outcomes of households. Renters and dwelling status have no statistically significant effect on both health outcomes holding all other factors constant.

Contrary to expectation, poor household is negatively associated with reported ill-health and frequency of ill-health. Based on the LPM, the probability of reporting ill-health and frequently reporting to a health facility due to ill-health is $10 \%$, respectively lower for poor households relative to non-poor households. With respect to the probit estimates, the results show that the probability of reporting ill-health and frequently reporting to a health facility due to ill-health is $29 \%$, respectively lower for poor households relative to non-poor households. Food hardship is positively associated with health outcomes indicating that food-insecure households are more likely to report negative health outcomes. The marginal effect suggests that the probability of reporting ill-health and frequently reporting to a health facility due to ill-health is $3 \%$ and $2 \%$, respectively higher for food-insecure households relative to food-secure households. With respect to the probit estimates, the results show that food-insecure households are $9 \%$ and $8 \%$, respectively more likely to report ill-health and frequently report to a health facility due to ill-health relative to food secured households. The results imply a strong association between food security and health outcomes. Households are more likely to report better health outcomes when policies that ensure 
high agricultural productivity and employment generation are vigorously pursued. Such policies have the potential of increasing access to food and income, thus lowering the negative health outcomes of the households.

Table 7: LPM and Probit estimates of SBF adoption on health outcomes

\begin{tabular}{|c|c|c|c|c|}
\hline \multirow[b]{2}{*}{ Variables } & \multicolumn{2}{|c|}{ LPM model } & \multicolumn{2}{|c|}{ Probit model } \\
\hline & Reported ill-health & $\begin{array}{c}\text { Frequency of } \\
\text { ill-health }\end{array}$ & Reported ill-health & $\begin{array}{l}\text { Frequency of } \\
\text { ill-health }\end{array}$ \\
\hline \multirow[t]{2}{*}{ Solid biomass fuel } & $0.045 * * *$ & $0.039 * *$ & $0.157 * * *$ & $0.142 * *$ \\
\hline & $(0.016)$ & $(0.015)$ & $(0.057)$ & $(0.057)$ \\
\hline \multirow[t]{2}{*}{ Renting ( $1=$ rent $)$} & -0.009 & -0.007 & -0.035 & -0.029 \\
\hline & $(0.010)$ & $(0.010)$ & $(0.033)$ & $(0.034)$ \\
\hline \multirow[t]{2}{*}{ Dwelling (1=compound) } & -0.012 & -0.011 & -0.031 & -0.027 \\
\hline & $(0.009)$ & $(0.009)$ & $(0.029)$ & $(0.029)$ \\
\hline \multirow[t]{2}{*}{ Poverty status ( $1=$ poor $)$} & $-0.099 * * *$ & $-0.095 * * *$ & $-0.293 * * *$ & $-0.286^{* * *}$ \\
\hline & $(0.011)$ & $(0.011)$ & $(0.036)$ & $(0.036)$ \\
\hline \multirow[t]{2}{*}{ Food hardship } & $0.029 * * *$ & $0.024 * *$ & $0.094 * * *$ & $0.078 * *$ \\
\hline & $(0.010)$ & $(0.009)$ & $(0.030)$ & $(0.031)$ \\
\hline \multirow[t]{2}{*}{ Location (1=Urban) } & 0.010 & 0.008 & 0.033 & 0.026 \\
\hline & $(0.011)$ & $(0.010)$ & $(0.033)$ & $(0.033)$ \\
\hline Socio-economic controls & Yes & Yes & Yes & Yes \\
\hline Geographical controls & Yes & Yes & Yes & Yes \\
\hline Housing controls & Yes & Yes & Yes & Yes \\
\hline Non-biomass users mean & {$[0.206]$} & [0.203] & [0.206] & [0.203] \\
\hline \multirow[t]{2}{*}{ Constant } & $0.061 * *$ & $0.066 * *$ & $-1.299 * * *$ & $-1.293 * * *$ \\
\hline & $(0.028)$ & $(0.028)$ & $(0.095)$ & $(0.096)$ \\
\hline Observations & 10,623 & 10,623 & 10,623 & 10,623 \\
\hline R-squared & 0.066 & 0.065 & & \\
\hline
\end{tabular}

\subsection{Bivariate probit estimates of determinants of solid biomass fuel adoption}

The biprobit results of the association between the adoption of SBF for cooking and health outcomes are reported in Table 8. Comparatively, the magnitude of the marginal effect of SBF adoption is higher for the biprobit model relative to the LPM and the probit models. There is a model improvement in the health outcomes following the correction in the endogeneity of SBF 
adoption. The LPM and probit models were underestimating the effect of SBF adoption on the health outcomes assuming the data is consistent and best fits the distributional assumptions of the biprobit model. After correcting for the potential endogeneity in SBF adoption, the result shows that adopters of SBF are $25 \%$ more likely to report ill-health and $25 \%$ more likely to frequently report to a health facility due to ill-health relative to non-adopters of SBF. Consistent with the LPM and probit models, renting is not statistically significantly associated with health outcomes. However, households who live in a compound house are $2 \%$ more likely to report ill-health and $2 \%$ more likely to frequently report to a health facility due to ill-health relative to households who dwell in private apartments. The result suggests that private-occupancy dwellers are less likely to interact with neighbours who are likely to be potential carriers of a disease, thus, reducing the potential risk of contracting an illness. Similarly, compound house dwellers frequently share household resources with neighbours which can serve as a potential source of contracting communicable diseases.

In contrast to the earlier findings (LPM and probit models), poor households are 9\%, respectively more likely to report ill-health and frequently report to a health facility due to ill-health relative to non-poor households. The strong association between poverty and health outcomes underscores the need for pro-poor policies that directly target the poor with the aim of eliminating extreme poverty. Empowering households economically can liberate them from the vicious cycle of poverty thereby improving their health outcomes. Food hardship is positively associated with an increase in health outcomes. The result suggests that food-insecure households are $3 \%$ more likely to report ill-health and 3\% more likely to frequently report to a health facility when compared to 
food-secure households. Improving access to food is necessary to reduce the potential healthrelated problems faced by households.

Table 8: Biprobit estimates of the effects of adoption of SBF on health outcomes

\begin{tabular}{|c|c|c|c|c|}
\hline \multirow[b]{2}{*}{ Variables } & \multicolumn{2}{|c|}{ Reported ill-health } & \multicolumn{2}{|c|}{ Frequency of ill-health } \\
\hline & $\begin{array}{c}\text { Marginal } \\
\text { effect }\end{array}$ & $\begin{array}{c}\text { Std } \\
\text { Error }\end{array}$ & $\begin{array}{c}\text { Marginal } \\
\text { effect }\end{array}$ & $\begin{array}{c}\text { Std } \\
\text { Error }\end{array}$ \\
\hline Solid biomass fuel & $0.247 * *$ & 0.104 & $0.245^{* *}$ & 0.103 \\
\hline Renting ( $1=$ rent $)$ & -0.007 & 0.011 & -0.005 & 0.011 \\
\hline Dwelling ( $1=$ compound) & $-0.021 *$ & 0.011 & $-0.019 *$ & 0.011 \\
\hline Poverty status $(1=$ poor $)$ & $0.093 * * *$ & 0.011 & $0.090 * * *$ & 0.011 \\
\hline Food hardship & $0.033 * * *$ & 0.010 & $0.028 * * *$ & 0.010 \\
\hline Location (1=Urban) & 0.008 & 0.010 & 0.006 & 0.010 \\
\hline Socio-economic controls & Yes & & Yes & \\
\hline Geographical controls & Yes & & Yes & \\
\hline Housing controls & Yes & & Yes & \\
\hline Non-biomass users mean & [0.206] & & [0.203] & \\
\hline Wald chi2(56) & $1268 * * *$ & & $1258 * * *$ & \\
\hline /athrho & $-0.349 *$ & 0.204 & $-0.360 *$ & 0.204 \\
\hline Wald test rho chi2(1) & $2.932 *$ & & $3.119^{*}$ & \\
\hline Observations & 10,623 & & 10,623 & \\
\hline
\end{tabular}

Notes: Biprobit estimates of average marginal effects are reported. Means of the dependent variable for the omitted comparison group (non-users of biomass) are presented in brackets. Robust standard errors are in parentheses. Significance at 10\%, 5\%, and $1 \%$ are indicated by $* * *$, and $* * *$, respectively.

\section{Discussion}

This study investigates the effect of SBF adoption on health outcomes in Ghana using observational data. About $93 \%$ of the sampled households in Ghana (more dominant in rural areas) use biomass solid fuel for cooking, which is consistent with earlier findings by Martey, (2019). The results of the study revealed a significant variation in the health outcomes of adopters of SBF and non-adopters of SBF. Adopters of SBF use either wood, charcoal, or crop residue/animal waste for cooking. The study revealed that non-adopters of SBF are less likely to report ill-health and 
frequently report to a health facility due to ill-health. The positive effect of SBF adoption on reported ill-health and frequently reporting to a health facility due to ill-health may be explained through two main channels. First, the use of SBF is associated with the emission of harmful smoke which is detrimental to human lives. Second, the duration of the exposure due to the duration of cooking may expose households to the harmful effect of the smoke. According to Bensch \& Peters (2015), most households cook inside an enclosed kitchen with little or no ventilation thus exposing them to the harmful effect of the smoke.

The result is consistent with previous studies that show that the use of SBF increases the levels of indoor air pollutants and poisonous gases such as carbon monoxide due to incomplete combustion of SBF. Exposure to these harmful particulate matters and noxious gases can have serious health implications therefore, the need to promote improved cookstoves and make it more affordable to households. In addition, the use of SBF contributes largely to global warming thus the need to minimize SBF and promote safer alternative fuels such as liquified petroleum gas (LPG). In a separate analysis (Table A2), the adoption of LPG reduces the probability of reporting ill-health and frequently reporting to a health facility due to ill-health, although the result is not significant. The insignificance may be due to the low number of users of the LPG in the sample households. Nevertheless, sustained adoption of the LPG depends largely on its affordability and availability.

Heterogeneity analysis of the use of SBF reveals a differential effect (Table 9). Comparatively, the use of wood for cooking has a relatively higher effect on health outcomes than the use of charcoal. The use of wood increases the probability of reporting ill-health and frequently reporting to a health facility due to ill-health by $9 \%$ each, respectively. In contrast, the use of charcoal increases 
the probability of reporting ill-health and frequently reporting to a health facility due to ill-health by $8 \%$ each, respectively. The results indicate that the use of wood for cooking contributes largely to the health implications of SBF adoption. Fetching of wood for cooking has serious implications on the forest and may lead to the loss of biodiversity with a subsequent negative impact on household wellbeing.

Table 9: Heterogeneity effect of solid biomass fuel adoption on health outcomes

\begin{tabular}{lccccc}
\hline \multirow{2}{*}{ Variables } & \multicolumn{2}{c}{ Reported ill-health } & & \multicolumn{2}{c}{ Frequency of ill-health } \\
\cline { 2 - 3 } \cline { 5 - 6 } & $\begin{array}{c}\text { Marginal } \\
\text { effect }\end{array}$ & $\begin{array}{c}\text { Std } \\
\text { Error }\end{array}$ & & $\begin{array}{c}\text { Marginal } \\
\text { effect }\end{array}$ & $\begin{array}{c}\text { Std } \\
\text { Error }\end{array}$ \\
\hline Wood & $0.085^{* *}$ & 0.035 & & $0.086^{* *}$ & 0.035 \\
Charcoal & $0.077^{* *}$ & 0.037 & & $0.075^{* *}$ & 0.036 \\
Dwelling & -0.006 & 0.009 & & -0.005 & 0.009 \\
Renting & -0.011 & 0.011 & & -0.009 & 0.010 \\
Demographic and economic & Yes & & & Yes & \\
Geographic controls & Yes & & & Yes & \\
Housing controls & Yes & & & Yes & \\
Observations & 10,623 & & & 10,623 & \\
\hline
\end{tabular}

The households were stratified into four quartiles based on income and the effect of the adoption of SBF on health outcomes were computed for each income quartile (Table 10). The same set of controls (socio-economic, geographic, and housing) used previously were included in the estimation. The effect of the SBF adoption on health outcomes was observed in the second- and fourth-income quartiles. However, the magnitude of the effect was the same. The results of the study suggest that the health implications of using SBF are similar for all households irrespective of income status. The promotion of clean fuel must be encouraged across all the different income segments households. 
The role of information in the choice of SBF cannot be overemphasized. Individuals make decisions based on their accumulated information acquired through experience and from external sources. Information reduces the uncertainty associated with the use of a new product or reemphasizes the importance of using and making modifications to an existing product with the objective of improving efficiency. When households have full information about the health implications of using SBF, they may act in a manner leading to behavior modifications with subsequent improvement in their health outcomes. Improving information flow between landlords and tenants will lead to an optimal investment decision with a long-term improved health effect.

Table 10: Differential effect of biomass adoption (stratification by income)

\begin{tabular}{lcccc}
\hline Income & \multirow{2}{*}{ quartiles } & \multirow{2}{*}{ Obs. } & \multirow{2}{*}{ Welfare } & \multicolumn{2}{c}{ Health outcome effects } \\
\cline { 4 - 5 } First & 2,655 & 892 & -0.111 & Frequency of ill-health \\
& & & $(0.206)$ & -0.151 \\
Second & 2,655 & 1,974 & $0.491 * * *$ & $(0.213)$ \\
& & & $(0.093)$ & $0.470^{* * *}$ \\
Third & 2,655 & 3,327 & 0.013 & $(0.110)$ \\
& & & $(0.182)$ & -0.028 \\
Fourth & 2,655 & \multirow{2}{*}{7,146} & $0.471 * * *$ & $(0.193)$ \\
& & & $(0.092)$ & $0.440^{* * *}$ \\
\hline
\end{tabular}

Notes: The numbers in parentheses are standard errors. Obs. Represent the number of observations. Significance at $1 \%$ is indicated by $* * *$.

\section{Conclusion and policy implications}

The adoption of solid biomass fuel (wood, charcoal, and crop residue/animal waste) has been widely studied in sub-Saharan Africa and globally. Nevertheless, only a few studies have looked at the health implications of the SBF using quasi-experiment and randomized control trials. Despite the significant contributions to the health and energy literature, there is a gap in terms of how dwelling and rental status contributes to the adoption of SBF and their effect on health outcomes within a developing context. This study analyzed the effect of using SBF on household health outcomes (measured as reported ill-health and reporting frequently to a health facility due 
to ill-health). Wood is the main SBF used by the majority (61\%) of the sampled households for cooking. The annual expenditure on wood, charcoal, and crop residue/animal waste for cooking are US\$56.33, US\$62.72, and US\$39.19, respectively.

The first stage results showed that household size, number of males between 5 to 18 years, rental and dwelling status, food hardship, and information about SBF, and geographical controls significantly influence the adoption of SBF for cooking. The rental and dwelling status of households play a significant role in the choice of energy for cooking. In comparison to the owneroccupied unit, renters were less likely to adopt SBF for cooking. Compared to private occupants, households who dwell in a compound house were more likely to use SBF for cooking. The promotion of clean fuel for cooking must principally target renters and private occupants while conscious effort in terms of sensitization must be targeted towards the owner-occupied unit and compound house dwellers.

Results from the biprobit estimates indicate that the adoption of SBF for cooking increases the probability of a household reporting ill-health and reporting frequently to a health facility by $25 \%$ each, respectively. The use of wood for cooking constitutes the highest proportion of the observed negative health effects from the heterogeneity analysis. The implications of the result are that if the current trend of using SBF is not curtailed, the health implications on humans will worsen which may further decrease the active labour force thus, reducing productivity. LPG, an alternative source of clean energy fuel for cooking has been widely promoted, however, affordability remains a challenge to most of the households. Promoting more cleaner fuel for cooking and making it affordable to households will have far-reaching health benefits. 
Relative to private occupant dwellers, households that dwell in compound houses are $2 \%$ less likely to report ill-health and $2 \%$ less likely to report frequently to a health facility due to ill-health. Surprisingly, households who dwell in a compound house are more likely to adopt SBF but less likely to be affected negatively in terms of their health outcomes. This could be the case where compound dwellers share a common kitchen which is a typical practice within the rural African setting and may not directly bear the consequences of the smoke exposure. However, there is the need to further explore the relationship between duration of exposure, dwelling status, energy use, and health outcomes using a randomized control trial or a panel data. The differential analysis revealed that households within the second- and fourth-income quartiles have similar health effect due to the adoption of SBF for cooking.

The main implication of the study is that discouraging the use of SBF for cooking across all income segments will improve health outcomes in the long-term. Government programs and policies that aim at encouraging the use of clean fuel for cooking must target private occupant home dwellers and homeowners. Information campaigns about clean energy must be vigorously pursued to increase the use of clean energy and improve health outcomes.

The study is limited in terms of using a self-reported health outcome instead of using objective indicators. However, the objective measurement of health outcomes in a typical survey is expensive and may be associated with a trade-off between accuracy and a Hawthorne effect. Second, the study is unable to link SBF to a specific illness such as pneumonia or lung-related diseases has been done elsewhere and some parts of SSA. The lack of panel data for this study limits the analysis to a one-period analysis thus eliminating the dynamics in terms of adoption of 
SBF and the associated effect on health outcomes. Despite the limitations, the study makes significant contribution to the energy and health literature by providing an indication of the health outcomes associated with a specific choice of SBF. The study further accounts for the role of rental status and dwelling mode in the choice of SBF and their effect on reported health outcomes.

\section{Declarations}

Ethics approval and consent to participate

Not applicable

\section{Consent for publication}

Not applicable

\section{Availability of supporting data}

The authors do not have the right to share the data but available upon request.

\section{Competing interests}

The authors declare that they have no competing interests both financial and non-financial.

\section{Funding}

There is no funding support for this study.

\section{Authors' Contribution}

EM conceptualized the research idea, requested for data, analyze data and approved the final manuscript.

\section{Acknowledgments}

This study used the Ghana Living Standard Survey Seven (GLSS 7) data provided by the Ghana Statistical Service (GSS). The Savanna Agricultural Research Institute (SARI) of the Council for Scientific and Industrial Research (CSIR) is acknowledged for the administrative support.

\section{References}

Acosta, P. (2011). School attendance, child labour, and remittances from international migration in El Salvador. Journal of Development Studies, 47(6), 913-936.

AGECC (Advisory Group on Energy and Climate Change). 2010. Energy for a Sustainable Future. New York: United Nations.

Altonji, J. G., Elder, T. E., \& Taber, C. R. (2005). An evaluation of instrumental variable strategies for estimating the effects of catholic schooling. Journal of Human resources, 40(4), 791-821. 
Bailis, R., Drigo, R., Ghilardi, A., \& Masera, O. (2015). The carbon footprint of traditional woodfuels. Nature Climate Change, 5(3), 266-272.

Baiyegunhi, L. J. S., \& Hassan, M. B. (2014). Rural household fuel energy transition: evidence from Giwa LGA Kaduna State, Nigeria. Energy for sustainable development, 20, 30-35.

Bensch, G., Grimm, M., \& Peters, J. (2015). Why do households forego high returns from technology adoption? Evidence from improved cooking stoves in Burkina Faso. Journal of Economic Behavior \& Organization, 116, 187-205.

Bensch, G., \& Peters, J. (2015). The intensive margin of technology adoption-Experimental evidence on improved cooking stoves in rural Senegal. Journal of health economics, 42, 44-63.

Clough, L. (2012). The Improved Cookstove Sector in East Africa: Experience from the Developing Energy Enterprise Programme (DEEP). London, UK: GVEP-Global Village Energy Partnership International, 108.

Dherani, M., Pope, D., Mascarenhas, M., Smith, K. R., Weber, M., \& Bruce, N. (2008). Indoor air pollution from unprocessed solid fuel use and pneumonia risk in children aged under five years: a systematic review and meta-analysis. Bulletin of the World Health Organization, 86, 390-398C.

Gebreegziabher, Z., Beyene, A. D., Bluffstone, R., Martinsson, P., Mekonnen, A., \& Toman, M. A. (2018). Fuel savings, cooking time and user satisfaction with improved biomass cookstoves: Evidence from controlled cooking tests in Ethiopia. Resource and Energy Economics, 52, 173185.

Gould, C. F., \& Urpelainen, J. (2018). LPG as a clean cooking fuel: Adoption, use, and impact in rural India. Energy Policy, 122, 395-408.

Gupta, G., \& Köhlin, G. (2006). Preferences for domestic fuel: analysis with socio-economic factors and rankings in Kolkata, India. Ecological Economics, 57(1), 107-121.

Han, S., \& Vytlacil, E. J. (2017). Identification in a generalization of bivariate probit models with dummy endogenous regressors. Journal of Econometrics, 199(1), 63-73.

Hanna, R., Duflo, E., \& Greenstone, M. (2016). Up in smoke: the influence of household behavior on the long-run impact of improved cooking stoves. American Economic Journal: Economic Policy, 8(1), 80-114.

International Energy Agency (IEA) (2019). "SDG7: Data and Projections", IEA, Paris https://www.iea.org/reports/sdg7-data-andprojections.

Johnson, M. A., \& Chiang, R. A. (2015). Quantitative guidance for stove usage and performance to achieve health and environmental targets. Environmental Health Perspectives, 123(8), 820-826.

Kan, X., Chiang, C. Y., Enarson, D. A., Chen, W., Yang, J., \& Chen, G. (2011). Indoor solid fuel use and tuberculosis in China: a matched case-control study. BMC Public Health, 11(1), 498. 
Lay, J., Ondraczek, J., \& Stoever, J. (2013). Renewables in the energy transition: Evidence on solar home systems and lighting fuel choice in Kenya. Energy Economics, 40, 350-359.

Lim, S. S., Vos, T., Flaxman, A. D., Danaei, G., Shibuya, K., Adair-Rohani, H., ... \& Aryee, M. (2012). A comparative risk assessment of burden of disease and injury attributable to 67 risk factors and risk factor clusters in 21 regions, 1990-2010: a systematic analysis for the Global Burden of Disease Study 2010. The lancet, 380(9859), 2224-2260.

Malla, S., \& Timilsina, G. R. (2014). Household cooking fuel choice and adoption of improved cookstoves in developing countries: a review. The World Bank.

Maria de Fatima, S. R., Zahran, S., \& Bucini, G. (2010). On the adoption of electricity as a domestic source by Mozambican households. Energy Policy, 38(11), 7235-7249.

Martey, E. (2019). Tenancy and energy choice for lighting and cooking: Evidence from Ghana. Energy Economics, 80, 570-581.

Martin, W. J., Glass, R. I., Balbus, J. M., \& Collins, F. S. (2011). A major environmental cause of death. Science, 334(6053), 180-181.

McCracken, J., Smith, K. R., Stone, P., Díaz, A., Arana, B., \& Schwartz, J. (2011). Intervention to lower household wood smoke exposure in Guatemala reduces ST-segment depression on electrocardiograms. Environmental health perspectives, 119(11), 1562-1568.

Mensah, J. T., \& Adu, G. (2015). An empirical analysis of household energy choice in Ghana. Renewable and Sustainable Energy Reviews, 51, 1402-1411.

Miller, G., \& Mobarak, A. M. (2015). Learning about new technologies through social networks: experimental evidence on nontraditional stoves in Bangladesh. Marketing Science, 34(4), 480499.

Mobarak, A. M., Dwivedi, P., Bailis, R., Hildemann, L., \& Miller, G. (2012). Low demand for nontraditional cookstove technologies. Proceedings of the National Academy of Sciences, 109(27), 10815-10820.

Mortimer, K., Ndamala, C. B., Naunje, A. W., Malava, J., Katundu, C., Weston, W., ... \& Wang, D. (2017). A cleaner burning biomass-fuelled cookstove intervention to prevent pneumonia in children under 5 years old in rural Malawi (the Cooking and Pneumonia Study): a cluster randomised controlled trial. The Lancet, 389(10065), 167-175.

Muller, C., \& Yan, H. (2018). Household fuel use in developing countries: Review of theory and evidence. Energy Economics, 70, 429-439.

Myers, E. (2020). Asymmetric information in residential rental markets: Implications for the energy efficiency gap. Journal of Public Economics, 190, 104251.

Ouedraogo, B. (2006). Household energy preferences for cooking in urban Ouagadougou, Burkina Faso. Energy policy, 34(18), 3787-3795. 
Pundo, M. O., \& Fraser, G. C. (2006). Multinomial logit analysis of household cooking fuel choice in rural Kenya: The case of Kisumu district. Agrekon, 45(1), 24-37.

Shindell, D., Kuylenstierna, J. C., Vignati, E., van Dingenen, R., Amann, M., Klimont, Z., ... \& Schwartz, J. (2012). Simultaneously mitigating near-term climate change and improving human health and food security. science, 335(6065), 183-189.

Smith, K. R., Frumkin, H., Balakrishnan, K., Butler, C. D., Chafe, Z. A., Fairlie, I., ... \& McMichael, A. J. (2013). Energy and human health. Annual Review of public health, 34, 159-188.

Souza, M. N. M. (2018). Why are rented dwellings less energy-efficient? Evidence from a representative sample of the US housing stock. Energy Policy, 118, 149-159.

Umberger, W. J., He, X., Minot, N., \& Toiba, H. (2015). Examining the relationship between the use of supermarkets and over-nutrition in Indonesia. American Journal of Agricultural Economics, $97(2), 510-525$.

United Nations. (2015). Transforming our world: The 2030 agenda for sustainable development. General Assembley 70 session.

UNECA (United Nations Economic Commission for Africa). 2014. Energy Access and Security in Eastern Africa: Status and Enhancement Pathways. Addis Abeba, Ethiopia: UNECA. http://bit.ly/2FAwNWL

Wooldridge, J.M., 2010. "Binary Response Models.” Econometric Analysis of Cross Section and Panel Data. 2nd ed. The MIT Press, pp. 561-642.

World Bank. 2011a. Household Cookstoves, Environment, Health, and Climate Change: A New Look at the Old Problem. Washington, D.C.: The World Bank.

World Health Organization. (2006). Fuel for life: household energy and health. Geneva: WHO

World Health Organization. (2014). WHO guidelines for indoor air quality: household fuel combustion. World Health Organization. http://apps.who.int/iris/

bitstream/10665/141496/1/9789241548885_eng.pdf (accessed Sept 26, 2020). 


\section{Appendices}

Table A1: Test of the validity of the instrument (falsification test)

\begin{tabular}{|c|c|c|c|c|c|c|}
\hline & \multicolumn{2}{|c|}{ SBF adoption } & \multicolumn{2}{|c|}{ Reported ill-health } & \multicolumn{2}{|c|}{ Frequency of ill-health } \\
\hline & Coefficient & Std. Error & Coefficient & Std. Error & Coefficient & Std. Error \\
\hline Information on SBF & $0.088 * *$ & 0.042 & 0.085 & 0.122 & 0.070 & 0.123 \\
\hline Constant & $1.086 * * *$ & 0.118 & -1.518 & 0.333 & $-1.520 * * *$ & 0.334 \\
\hline Wald chi2 (28) & $457.86^{* * *}$ & & $87.41 * * *$ & & $87.62 * * *$ & \\
\hline Observation & 10,623 & & 10,623 & & 10,623 & \\
\hline
\end{tabular}

Table A2: Biprobit estimates of the effects of adoption of LPG on health outcomes

\begin{tabular}{lcc}
\hline Variables & Reported ill-health & Frequency of ill-health \\
\hline LPG adoption & -0.296 & -0.392 \\
& $(0.350)$ & $(0.332)$ \\
Renting (1=rent) & -0.034 & -0.026 \\
& $(0.033)$ & $(0.034)$ \\
Dwelling (1=compound) & -0.026 & -0.023 \\
& $(0.029)$ & $(0.029)$ \\
Poverty status (1=poor) & $-0.299 * * *$ & $-0.294 * * *$ \\
Food hardship & $(0.036)$ & $(0.036)$ \\
& $0.083^{* * *}$ & $0.065^{* *}$ \\
Location (1=Urban) & $(0.032)$ & $(0.032)$ \\
& 0.052 & 0.052 \\
Socio-economic controls & $(0.039)$ & $(0.039)$ \\
Geographical controls & & Yes \\
Housing controls & Yes & Yes \\
Constant & Yes & Yes \\
& & $-1.156^{* * *}$ \\
Observations & $-1.152^{* * *}$ & $(0.082)$ \\
\hline
\end{tabular}

Notes: Robust standard errors are in parentheses. Significance at 5\%, and 1\% are indicated by **, and ***, respectively. 


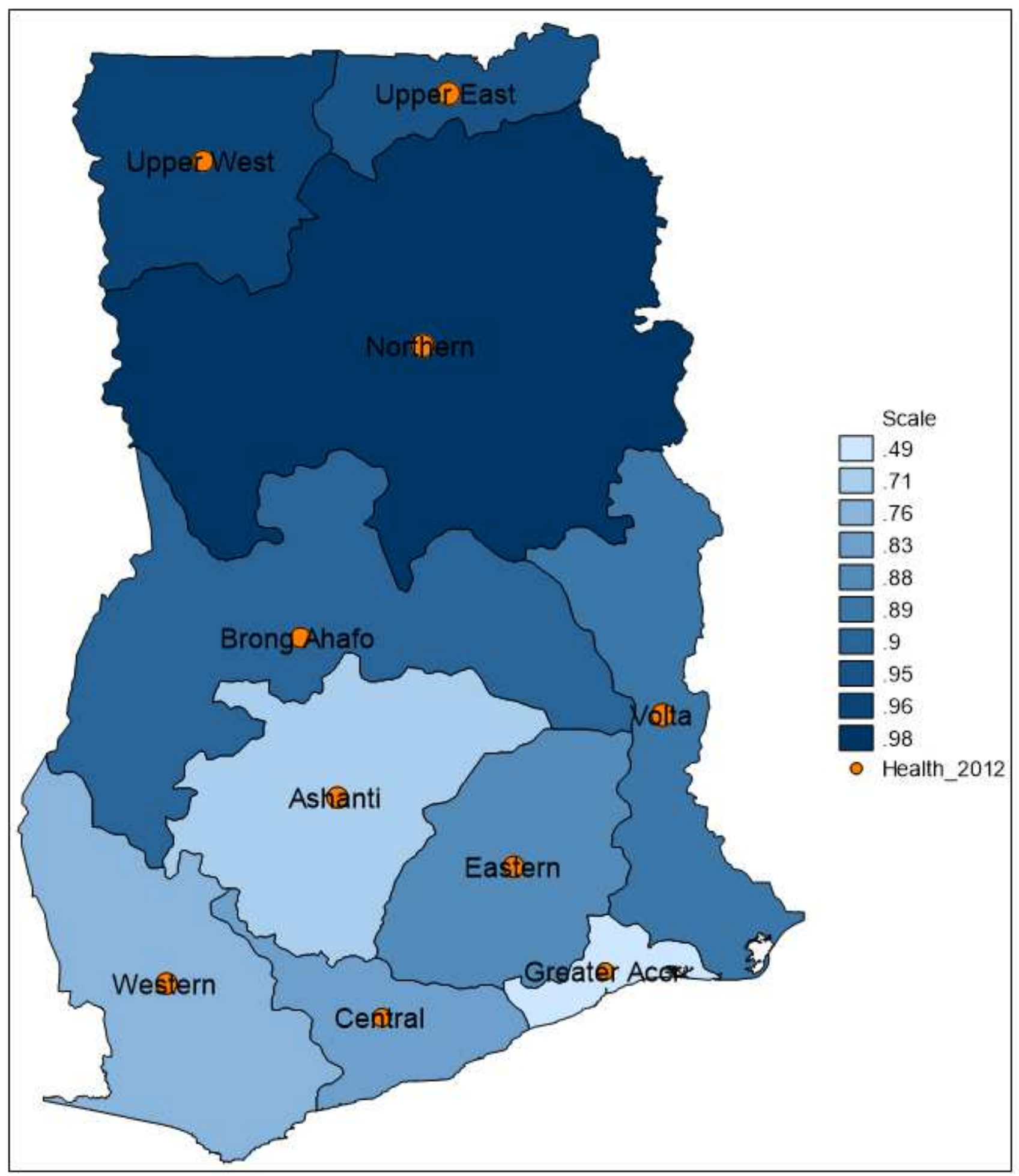

\section{Figure 1}

Solid biomass fuel and health outcomes for 2012 Note: The designations employed and the presentation of the material on this map do not imply the expression of any opinion whatsoever on the part of 
Research Square concerning the legal status of any country, territory, city or area or of its authorities, or concerning the delimitation of its frontiers or boundaries. This map has been provided by the authors.

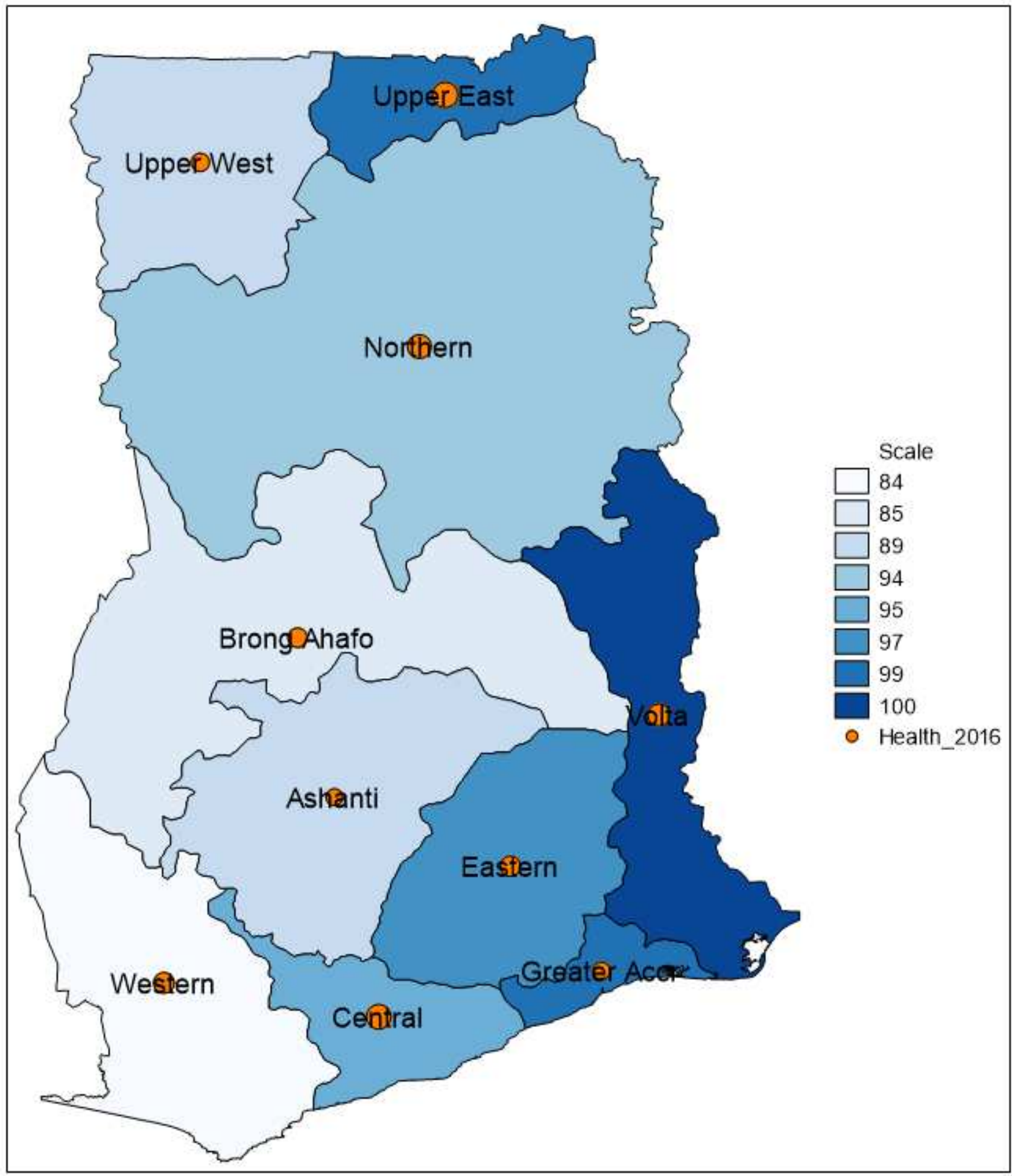

Figure 2

Solid biomass fuel and health outcomes for 2016 Note: The designations employed and the presentation of the material on this map do not imply the expression of any opinion whatsoever on the part of Research Square concerning the legal status of any country, territory, city or area or of its authorities, or concerning the delimitation of its frontiers or boundaries. This map has been provided by the authors. 

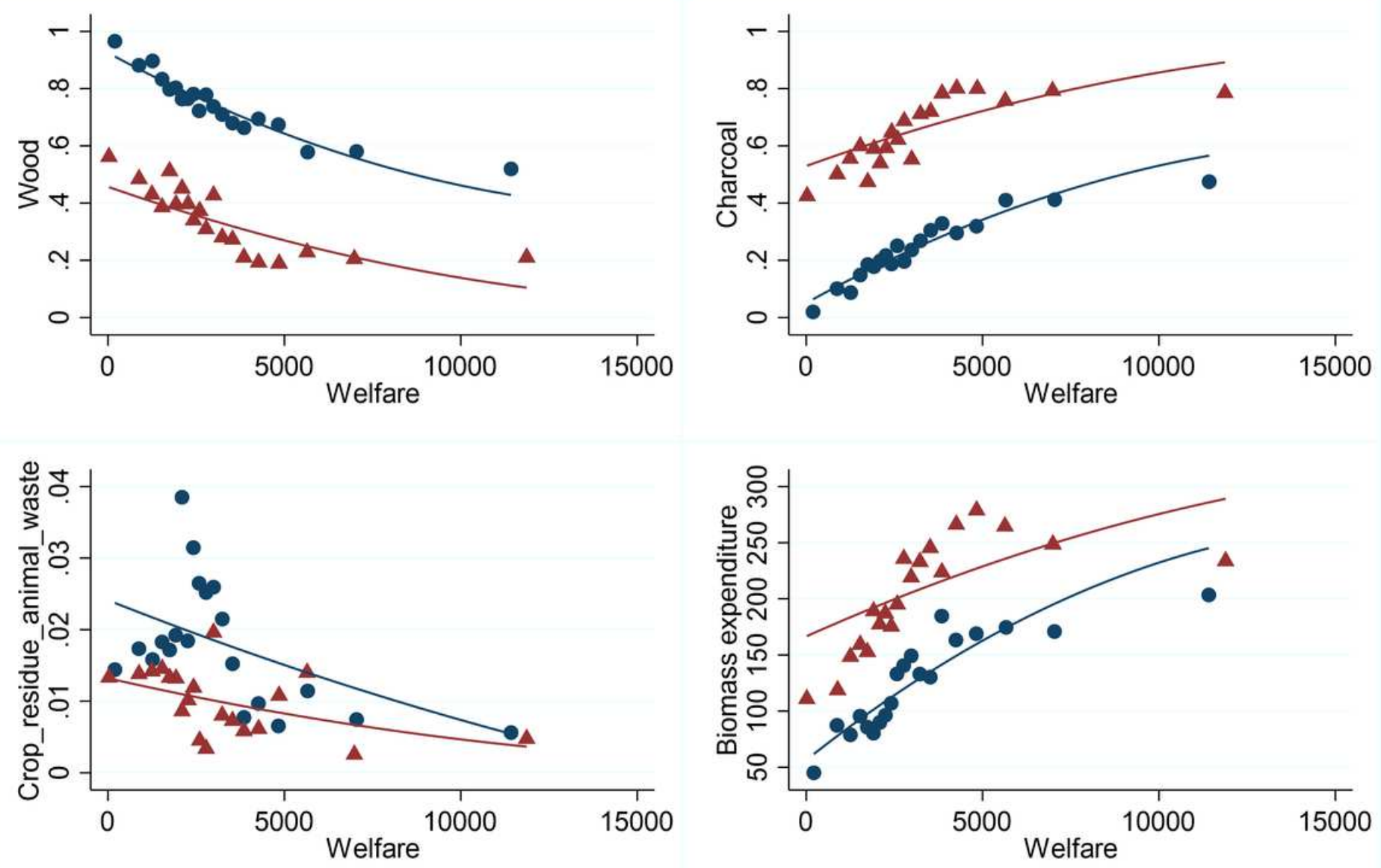

- Urban $\Delta$ Rural

Figure 3

Solid biomass fuel and expenditure by location

\section{Supplementary Files}

This is a list of supplementary files associated with this preprint. Click to download.

- Appendices.docx 